\title{
Systems mutual loadings of traction asynchronous cars
}

\author{
Andriy Afanasov, Oleksandr Shapovalov*, and Maryna Voitenko \\ Dnipro National University of Railway Transport named after Academician V. Lazaryan, 49000 Dnipro, Ukraine
}

\begin{abstract}
The review of methods of post-repair tests of traction asynchronous motors under conditions of locomotive depot is carried out. The necessity of introducing special stands for post-repair tests is shown in order to improve their quality, reduce the number of failures of service equipment, improve safety of the railway transport. Let's consider a question of power supply of the research asynchronous engine in wide frequency range and also a possibility of creation of the universal stand for testing important asynchronous engines of the electrorolling stock. Survey of possible versions of the scheme mutual loadings of asynchronous electrical machines which can be used for testing traction asynchronous engines of the rolling stock is executed. Such systems can be constructed both with use of the static converter of frequency, and without it. The given short characteristic of each alternative, certain advantages and shortcomings of each of system options. It is shown that systems with use of static converters of frequency differ in high power efficiency, allow to carry out tests in the wide frequency range of power supply, however have higher prime cost. Schemes without converters of frequency differ in smaller power efficiency, impossibility to carry out tests in the wide range of frequency of power supply, high level of consumption of reactive power. The results of the carried-out analysis can be used when choosing rational option of a system mutual loadings of asynchronous electric motors which will differ in higher functionality and power efficiency. Use of such systems will allow to lower capital expenditure for creation new and modernization of traction electrical machines that exist at the station for test.
\end{abstract}

\section{Introduction}

According to DSTU GOST 2582:2017 [1] electrical machines of the traction rolling stock of the main and industrial transport at acceptance tests for one hour at current which gives excess of temperature of windings which corresponds to excess of temperature at the nominal mode.In fact this value of current, which corresponding to the sentry of the mode.

Requirements of the corresponding standards and rules of repair of the traction and motorvagonny rolling stock of the main and industrial transport provide carrying out acceptance tests of everyone newly the manufactured or repaired traction electrocar [1]. These tests represent an important part of technological process of production or repair of the electrical machine, material expenses on which enter prime cost of end products. About $15 \%$ of energy are spent for Postrepair tests which is necessary for repair.

The quality of technical control which is carried out at acceptance tests of traction electrical machines in a final case defines reliability and non-failure operation work of the locomotive, and respectively and cost efficiency of rail transportation on the main and industrial transport. Tests for heating, check of frequency of rotation and reversal requires mandatory loadings of traction electrical machines [1] at the testing bench.

The largest power efficiency of acceptance tests can be reached by use of a system mutual loading of traction electrical machines [2].

\section{Analysis of literary data and statement of a problem}

The choice of the scheme of test of electrical machines is defined by the electric equipment of the test station, but it is possible to describe all of them a number of quantitative and qualitative parameters which allow to define efficiency of this technological process.

One of quantitative parameters is the power of the additional equipment which is defined by frequency rate in relation to the power of the tested electrical machine. Also this power determines the necessary area of the test station:

$$
K_{\mathrm{\kappa}}=\frac{P_{a e}}{P_{a m}},
$$

where $P_{a e}$ - total power of auxiliary equipment; $P_{a m}-$ the power of the engine examinee. 
The second parameter is quantity of the consumed electric power at tests. As examinees engines differ on power, it is possible to express this parameter in relative units and to call coefficient of profitability of the scheme. It will be equal:

$$
K_{\mathrm{e}}=\frac{P_{c}-P_{a m}}{P_{a m}},
$$

where $P_{c}$ - the power which is consumed by the stand; $P_{a m}$ - the power which is consumed by the examinee the engine.

From this point of view the most economic schemes of tests are schemes of tests of electrical machines on a method mutual loadings, when two electrical machines electrically and mechanically connected, so that one of them, working in the generator mode, gives all electric energy made by first to the second electrical machine, which works in the engine mode, and the last spends all mechanical energy for rotation of the first electric machine. Energy from the network is consumed only on a covering of losses in the scheme.

The most bulky and difficult there are schemes of tests of commutatorless traction electric motors of alternating current [3]. For schemes of direct test of loading it is frequency the operated asynchronous traction electric motors from a sinusoidal source of tension brought to [4-6] frequency rate of rated capacity makes from 3.5 to 7 , the coefficient of profitability from 0.25 to 0.75 , it means that the general power of the additional equipment exceeds the power of the examinee of the electric motor by 3.5-7 times, and electricity consumption by satellite machines which are included into the scheme makes $0.25-0.75$ capacities of the examinee of the engine. In the provided schemes the examinee the traction engine receives food from sources sinusoidal tension. Schemes are provided have higher power efficiency in comparison with schemes direct loadings, however have smaller power efficiency in comparison with schemes with the static converter of frequency.

In work [7] is considered methods of increase in efficiency due to reduction of number of the service equipment, and recalculation of current of the engine. However the offered method complicates tests of cars with ventilation.

In the modern asynchronous electric drive are used static converters with pulse-duration regulation of tension. In works [8-10] schemes of test of asynchronous traction engines with a power supply of the examinee of the engine from the frequency converter are developed.

However uniform standards which would regulate work of a system the frequency converter - the asynchronous engine is not developed for today.There is an incomplete number of standards and technical requirements to separate components of a control system of the asynchronous drive, such as frequency converter, filters, asynchronous engines [11-13].

The purpose of the work is definition of possible alternative versions of the scheme mutual loadings of asynchronous traction electrical machines, definition of the main characteristics of such systems, and carrying out their comparative analysis.

\section{Definitions of the conditions mutual loadings of asynchronous machines}

As is known from $[14,15]$ for ensuring process mutual loadings of electrical machines from the power point of view necessary following conditions:

- ensuring transfer of electric power from the generator to the engine;

- ensuring transfer of mechanical power from the engine to the generator;

- coverings of all losses which arise by transfer of power.

Power indicators of an electric way of compensation of magnetic and mechanical losses at mutual loading in traction electric motors are given in [16].

For introduction of the asynchronous machine to the generating mode it is necessary to provide the frequency of rotation of a rotor of the machine higher then frequencies of rotation of magnetic field of the machine, that is to provide negative slidings. This condition imposes additional restrictions for carrying out tests as at test of two identical machines necessary different frequencies of rotation of their rotors, or different frequencies of power supply.

Let's define necessary conditions for introduction of the asynchronous engine to the generating mode, as slidings for the generating mode is in limits $-\infty<\mathrm{s}<0$, then it is possible to determine the frequency of power supply of the engine as follows:

$$
\begin{aligned}
& n_{\mathrm{am}}=n_{\mathrm{smr}}\left(1-s_{\mathrm{e}}\right), \\
& n_{\mathrm{ag}}=n_{\mathrm{sgr}}\left(1-s_{\mathrm{g}}\right),
\end{aligned}
$$

where $n_{a m}$ - frequency of engine rotation; $n_{a g}-$ frequency of generator rotation; $s_{e}-$ size of sliding of the engine; $s_{g}-$ size of sliding of the generator; $n_{s m r}-$ synchronous frequency of engine rotation; $n_{s g r}-$ synchronous frequency of generator rotation.

It is possible to determine synchronous frequencies of rotation for each machinnes as follows:

$$
\begin{aligned}
& n_{s m r}=\frac{60 f_{\mathrm{e}}}{\mathrm{p}}, \\
& n_{\mathrm{sgr}}=\frac{60 f_{\mathrm{g}}}{\mathrm{p}},
\end{aligned}
$$

where $f_{e}$ - frequency of power supply of the engine; $f_{g}-$ frequency of power supply of the generator; $p$ - number of couples of poles of the electrical machine.

As the unification of shafts of rotors of asynchronous machines are possible with both by means of the coupling, and by means of a reducer (variator), It is necessary to consider two options: $n_{\partial}=n_{2}$ and $n_{\partial} \neq n_{2}$. 
Let's consider a condition of realization mutual loadings with an identical frequency of rotation of shaft of rotors and different frequency of supply voltages $n_{\partial}=n_{2}$ :

$$
\frac{60 f_{\mathrm{e}}}{\mathrm{p}}\left(1-s_{\mathrm{e}}\right)=\frac{60 f_{\mathrm{g}}}{\mathrm{p}}\left(1-s_{\mathrm{g}}\right) .
$$

From expression we will determine the frequency of power supply of the engine from the frequency converter:

$$
f_{\mathrm{e}}=f_{\mathrm{g}} \frac{1-s_{\mathrm{g}}}{1-s_{\mathrm{e}}} .
$$

In this dependence it should be noted that sliding of the generator is negative.

Let's consider a condition of realization mutual loadings with different frequencies of rotation of shaft of rotors $n_{\partial} \neq n_{2}$ in this form:

$$
\frac{n_{\mathrm{am}}}{n_{\mathrm{ag}}}=\frac{1-s_{\mathrm{e}}}{1-s_{\mathrm{g}}} .
$$

From the expression we will determine the necessary frequency of rotation of the generator in a form:

$$
n_{\mathrm{ag}}=n_{\mathrm{am}} \frac{1-s_{\mathrm{g}}}{1-s_{\mathrm{e}}} .
$$

Knowing frequencies of rotation of the engine and the generator it is possible to define the transfer relation of the gearing (variator):

$$
\mu=n_{\text {am }} \frac{n_{\text {ag }}}{n_{\text {am }}} .
$$

One more complexity of realization of a system mutual loadings of asynchronous is that the power of the asynchronous machines with an invariable frequency and supply voltage is sliding function, that is at increase in power consumption will increase slidings. It can be defined from this dependence:

$$
s=\frac{n_{1}-n_{2}}{n_{1}} .
$$

where $s$ - size of sliding of the asynchronous machine; $n_{l}$ - speed of rotation of magnetic field (synchronous speed); $n_{2}$ - speed of rotation of a rotor.

Let's express slidings $\mathrm{s}$ through angular speeds of rotation of magnetic field $\omega_{1}$ and a rotor $\omega_{2}$ :

$$
\begin{aligned}
& \omega_{1}=\frac{2 \pi n_{1}}{60}, \\
& \omega_{2}=\frac{2 \pi n_{2}}{60} .
\end{aligned}
$$

From where we will receive:

$$
\begin{aligned}
& n_{1}=\frac{60 \omega_{1}}{2 \pi}, \\
& n_{2}=\frac{60 \omega_{2}}{2 \pi},
\end{aligned}
$$

where $\omega_{1}$ - angular speed of rotation of stator magnetic field; $\omega_{2}-$ angular speed of rotation of a rotor.

We will substitute the received expressions in a sliding formula (12):

$$
s=\frac{\omega_{1}-\omega_{2}}{\omega_{1}} .
$$

We find out the effect of sliding on the power that is developing by the engine:

$$
\begin{gathered}
P_{1}=\frac{F_{1} l}{t}=\frac{F_{1} 2 \pi R}{T}=F_{1} R F \omega_{1}, \\
P_{2}=\frac{F_{2} l}{t}=\frac{F_{2} 2 \pi R}{T}=F_{2} R F \omega_{2},
\end{gathered}
$$

where $P_{1}$ - the power consumed by the electric motor; $P_{2}$ - power on a rotor shaft; $F_{1}$ - the electromagnetic force which affects a rotor; $F_{2}$ - the mechanical force which affects a rotor; $l$ - rotor circle length; $R$ - rotor radius.

From formulas (18) and (19) let's express angular frequencies of rotation of magnetic field $\omega_{1}$ and a rotor $\omega_{2}$ :

$$
\begin{aligned}
& \omega_{1}=\frac{P_{1}}{F_{1} R}, \\
& \omega_{2}=\frac{P_{2}}{F_{2} R} .
\end{aligned}
$$

Taking the ratio $\omega_{1}-\omega_{2}$ to $\omega_{1}$ we get:

$$
\frac{\omega_{1}-\omega_{2}}{\omega_{1}}=\frac{1}{\omega_{1}}\left(\frac{P_{1}}{F_{1} R}-\frac{P_{2}}{F_{2} R}\right) .
$$

As in the settled mode $F_{1}=F_{2}$ forces are balanced, we get such ratio:

$$
\frac{\omega_{1}-\omega_{2}}{\omega_{1}}=\frac{P_{1}-P_{2}}{F_{1} R \omega_{1}} .
$$

Taking into account formulas (17) and (18) we get:

$$
s=\frac{P_{1}-P_{2}}{P_{1}} .
$$

From where we have:

$$
P_{2}=P_{1}(1-s) \text {. }
$$

For today while carrying out tests of asynchronous machines widely use static converters of frequency. This 
is due to the fact that, according to [8] at tests the engine has to receive power supply from same power sources as well as during the work. However during the work the converter of frequency brings additional losses in the engine which are connected by it with the highest harmonicas of current. It is possible to reduce these losses when the frequency of switching of power keys of the converter having increased however in this case losses increase by switching in the converters. For this reason the frequency of pulse-duration modulation of modern converters of frequency is in limits $10-20 \mathrm{kHz}$. In general system development mutual loading with high power to indicators is rather difficult task which demands an integrated approach.

\section{Possible variations of schemes mutual loadings}

The scheme of tests of asynchronous engines with the mechanical converter of frequency is submitted in (Fig. 1)

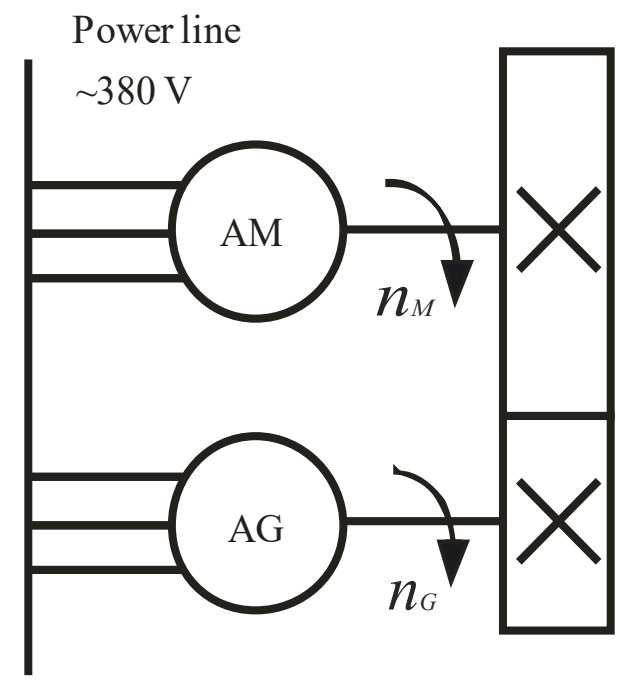

Fig. 1. The scheme mutual loadings of asynchronous engines with the mechanical converter of frequency

This scheme represents two same asynchronous machines, the asynchronous engine and the asynchronous generator, the shafts of the rotors are interconnected by a reducer (multiplier). In machines of low and average power instead of a reducer also possible use of belt variators, or hydraulic drives. The main feature of the scheme is that frequencies of rotation of shaft of rotors of the engine and the generator differ. At the same time there is possible a connection of both machines to the general network with power supply with an identical frequency of current. At test of engines of low and average power for smooth regulation of the trancemission ratio there will be expedient use of belt variators. It should be noted that when using the mechanical converter of frequency the scheme has rather high coefficient of power efficiency, as the scheme provides minimum number of possible service equipment. For carrying out tests of engines of high power can be used the scheme, which is submitted in (Fig.2).

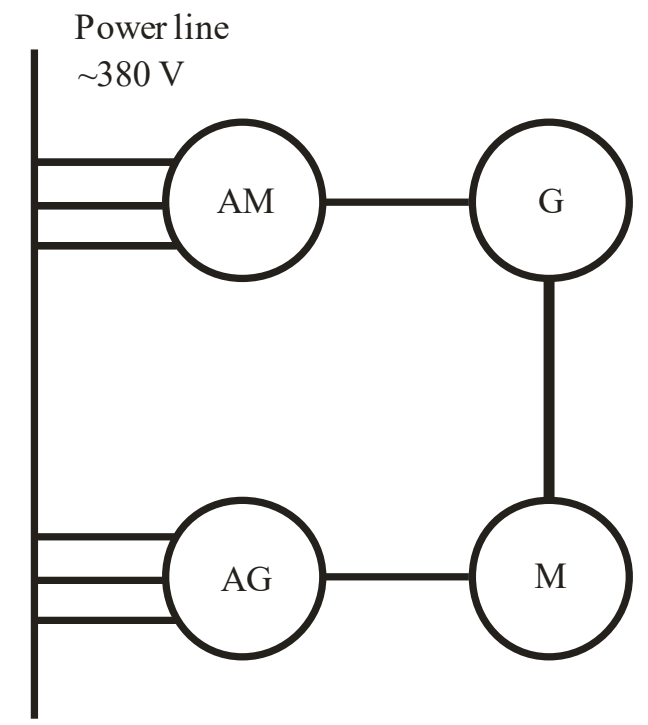

Fig. 2. The scheme mutual loadings the asynchronous engine the asynchronous generator with a link of a direct current

This scheme consists of two machines of alternating current (the asynchronous engine and the asynchronous generator) and two machines of a direct current (the direct current motor and the direct current generator). The rotor of the asynchronous engine is connected to an anchor of the direct current generator, the rotor of the asynchronous generator is connected to an anchor of the direct current motor. In comparison with the previous option this scheme can be used at test of asynchronous traction engines of high power. However use of auxiliary machines in this scheme reduces profitability coefficient and also increases the area of the test station, necessary for placement of the equipment. Schemes with use of static converters of frequency differ in high power efficiency. The version of such scheme is given on (Fig. 3).

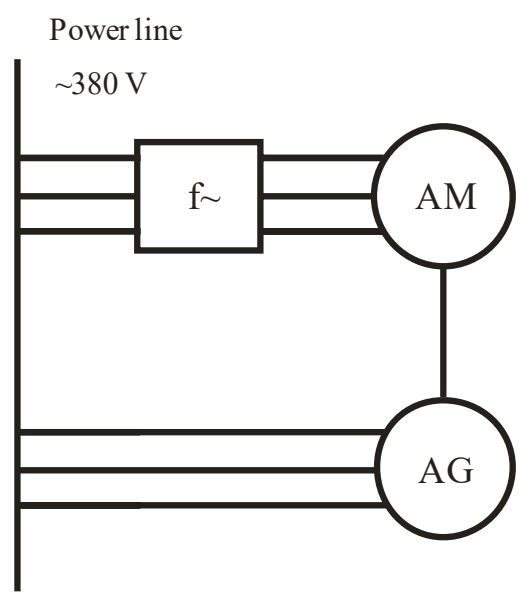

Fig. 3. The scheme mutual loadings of asynchronous engines with one converter of frequency

This scheme represents two same asynchronous machines, bring down rotors of which connected among themselves by means of the coupling. The asynchronous 
engine receives a power supply from the frequency converter. The generator works with excitation from network. As bring down rotors rotate with an identical frequency for introduction of the asynchronous engine to the mode of the generator it is necessary to increase the frequency of rotation of its rotor. By means of the converter of frequency it is possible to regulate smoothly the frequency of rotation of shaft of machines and consequently also power. Uses of small number of the service equipment provides high power efficiency of the scheme.

Lack of the schemes given above is the narrow range of examinees of frequencies, in fact it is possible to test engines with one certain frequency which is close to the frequency of a power line. For test of asynchronous machines in the wide range of the power supply frequencies the scheme is used with two converters of frequency provided on (Fig. 4).

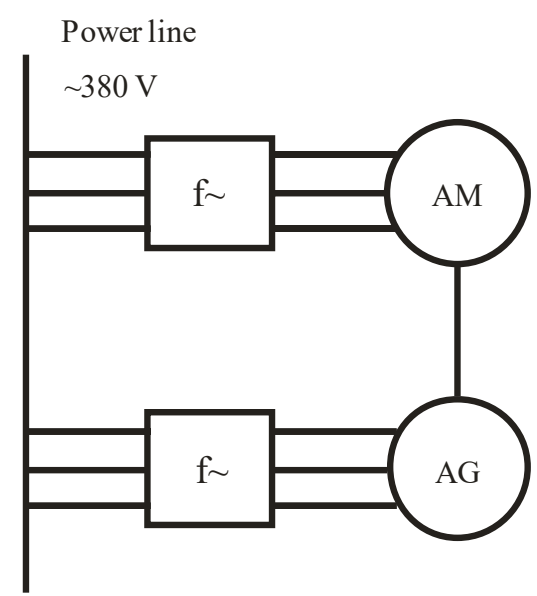

Fig. 4. The scheme mutual loadings of asynchronous engines with two converters of frequency

Feature of this scheme is use of two converters of frequency which allow to realize a system mutual loadings with any frequency of power supply of the engine and generator. At the same time the coefficient of power efficiency decreases and the number of the service equipment increases. The scheme with two converters of frequency and a link of a direct current allows to reduce losses during tests provided on (Fig. 5).

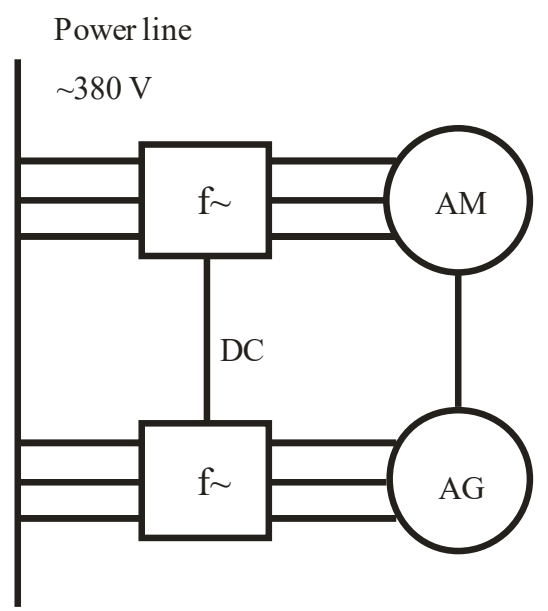

Fig. 5. The scheme mutual loadings of asynchronous engines with two converters of frequency and a link of a direct current

This scheme represents two same asynchronous machines, bring down rotors of which connected among themselves by means of the coupling. The asynchronous engine receives a power supply from the frequency converter. The induction generator also receives power from the frequency converter.

The unification of this scheme with the links of a direct current of converters of frequencies among themselves is feature of this scheme. This decision allows to increase coefficient of power efficiency in comparison with the scheme provided on (Fig. 4), due to reduction of number of transformations of energy. Electric energyIt which is developed by the generator gets to a link of a direct current of converters of frequency, and from it arrives to the engine. At the same time all advantages of the scheme remain provided on (Fig. 4).

The scheme of tests of asynchronous engines with one converter of frequency and a direct current generator provided on (Fig. 6).

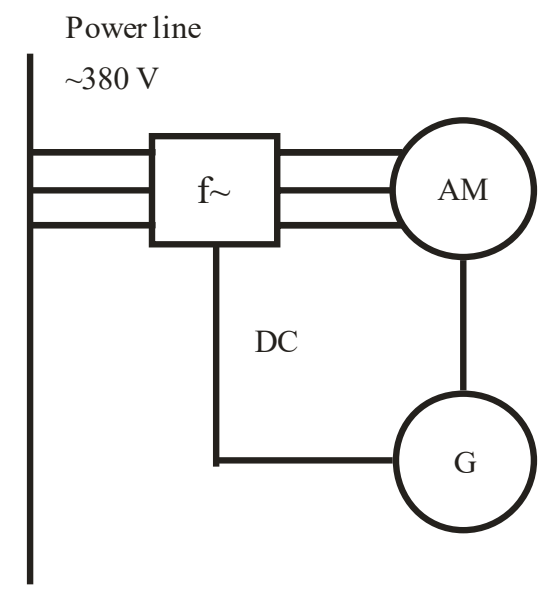

Fig. 6. The scheme mutual loadings the asynchronous engine the direct current generator

This scheme represents frequency converter, asynchronous engine and a direct current generator. The rotor of induction motor is connected to the rotor direct current generator. The asynchronous engine receives a power supply from the frequency converter. The generator is used to load the induction motor. Generator energy is fed to the direct current link of the frequency converter.

The advantage of this scheme is the ability to test over a wide range of power frequencies using only one frequency converter. The scheme also allows you to test engines of different power.

\section{Conclusions}

It was analyzed systems of mutual loading of threephase asynchronous engines, it is proved a possibility of realization mutual loadings both with the static converter of frequency, and without it. Each of the schemes mutual loadings has both the advantages and 
shortcomings. As a result of researches it was defined a condition of introduction of the asynchronous engine to the generator mode during the work in parallel with network. For common industrial electric motors of low power use of the scheme will be rational (Fig. 1), As possible use of a belt variator thanks to the profitability coefficient increases, and also it is possible to regulate the transfer relation smoothly. As the power of examinees of machines is low, during the work the scheme will consume low reactive power. The scheme (Fig. 1) is highlighted with the lowest cost as converters of frequency and also auxiliary machines are not its part.

For common industrial electric motors of an average and high power use of the scheme (Fig. 3) will be rational. Thanks to the converter of frequency it is possible to regulate smoothly the frequency of rotation of a rotor of the electric motor that provides input of the asynchronous engine in the generator mode and also to smoothly regulate electric motor power. For traction asynchronous electric motors of railway and industrial transport in which the frequency of power supply differs from common industrial there will be rational use of the scheme (Fig. 5). This scheme allows to realize any frequency of power supply of examinees of electrical machines. Thanks to the unification of links of a direct current of converters of frequency energy from the generator to the engine with the smallest number of transformations that allows to provide rather high effectiveness ratio, with the different frequencies of power supply of the electric motor other than the frequency of network.

\section{References}

1. GOST DSTU 2582:2017 The rotating traction electrical machines. General specifications (GOST 2582-2013, IDT; IEC 60349-1:2010, NEQ; IEC 60349-2:2010, NEQ), (2017)

2. H. K. Zherve, Industrial tests of electrical machines, publ. Energoatomizdat, 506 c., (1984)

3. V. H. Shcherbakov, Traction electric motors of electric locomotives, Nautilus Agency, 1998. - 672 c., (1998)

4. R. Y. Alkyn, E. A. Dolgosheyev, I. I. Tal'ya, I. L. Torgonskiy, The device for tests of the asynchronous traction engine with a short-circuited rotor, A.c. the USSR № 1352424A1, №42, (1987)

5. I. I. Tal'ya, The device for test of the asynchronous traction engine with a short-circuited rotor, pat. RF№ 2023274 (13) C1, №4, (1994)
6. I. I. Tal'ya, The device for tests of electrical machines of alternating current without collectors, Pat.№ 2071608, №1, (1997)

7. P. O. Loza, Improvement of power and other indicators of acceptance tests of traction engines of electric locomotives, Messenger DnipropetrovskNational University of Railway Transport named after Academician V. Lazaryan, 27, 81-83, (2008)

8. A. P. Kalinov, E. Y. Danchenko, O. V. Korsun', V. V. Lotous, Way of test of asynchronous engines under loading with use of converters of frequency, Pat.№ 117504 , Base of patents of Ukraine (2017)

9. D. I. Popov, The stand for test of asynchronous machines, Pat.RU186188U1 (2018)

10. V. V. Kharlamov, D. I. Popov, Snand of testing of asynchronous motors reciprocal load method, Pat.RU178716U1 (2018)

11.DSTU IEC/TS 60034-17:2009. The electrical machines rotating. Part 17. Asynchronous engines with a short-circuited rotor and power supply through the converters. Unit for application (IEC/TS 60034-17:2006, IDT) (2009)

12. DSTU EN 61800-3:2015/ Change №1:2015 (EN 61800-3:2004/A1:2012,IDT). Systems power to the electric drive with an adjustable speed. Part 3. Requirements to electromagnetic compatibility and special test methods (2015)

13.DSTU IEC 61800-2:2008. Adjustable speed electrical power drive systems. Part 2. General requirements and rated specifications of low-voltage, variable-frequency $A C$ drives. (IEC 61800-2:1998, IDT) (2008)

14. A. M. Afanasov, Electromechanical principles of providing mutual loading of electrical machines of a direct current, Messenger Dnipropetrovsk National University of Railway Transport named after Academician V. Lazaryan, 27, 42-46 (2009)

15. A. M. Afanasov, The systems of mutual loading of traction electrical machines of the constant and pulsing current, the monograph, Makovetsky, $248 \mathrm{p}$ (2012)

16. A. M. Afanasov, Power indicators of an electric way of compensation of magnetic and mechanical losses in traction electric motors at their mutual loading, Messenger DnipropetrovskNational University of Railway Transport named after Academician V. Lazaryan, 34, 65-68 (2010) 